\title{
Ceramic / Inorganic-Organic Nano-Hybrid Composites for Thermally Stable Insulation of Electrical Wires: Part I - Composition and Synthetic Parameters
}

\author{
Yong-Xin Pang and Simon N.B. Hodgson \\ School of Science, Engineering and Design \\ Teesside University \\ Middlesbrough TS1 3BX, United Kingdom
}

\begin{abstract}
Composite coatings comprising of particulate ceramic and silicon containing inorganicorganic nano-hybrids are synthesized and applied as high temperature capable coatings for electrical wire insulation. The nano-hybrids are synthesised from organosilanes bearing non-hydrolysable methyl, glycidyloxypropyl and phenyl groups. The molar ratios of organosilanes, acid catalysts and synthetic conditions are optimised to offer suitable mechanical and thermal performance to the composite coatings. Different particulate ceramics are tested in regard to their effects on mechanical stiffness of the resultant composite coatings. Vermiculite platelet is finally selected for its lower hardness. The mass ratio of nano-hybrids to platelets of 70:30 to 60:40 are found optimal for balanced performance in respect to thermal, mechanical and dielectric properties. Uniform composite coatings are produced on conductor wires using a reel-to-reel continuous coating process. Initial tests showed insulated wires have moderate mechanical flexibility, dielectric strength and excellent thermal stability, capable of withstanding over $1100 \mathrm{~V}$ AC potential after $500^{\circ} \mathrm{C}$ heating.
\end{abstract}

Index Terms - wire insulation, breakdown voltage, thermal stability, composite coatings, inorganic-organic nano-hybrids, ceramic platelets

\section{INTRODUCTION}

ORGANIC polymers and inorganic ceramics are both widely used as electrical insulators, but in very different contexts due to the nature of their materials. Polymers possess high dielectric strength and mechanical flexibility and toughness, and are most widely used electric insulators; ceramics have very high temperature stability but poor mechanical properties, and hence are mostly used in applications where high temperature stability is essential, like sheathed thermocouples. Polymer enamels are predominant wire insulation in current market for electrical machine windings. However the thermal stability of polymer materials places an upper-limit on the application temperature, and the highest temperature rating presently available is $240^{\circ} \mathrm{C}$ from polyimide enamelled wires, e.g. NEMA MW16-C and Thermex 240 . Nowadays, there is frequently a significant design need for flexible and versatile insulation materials capable of operating at temperatures well above the current limit of polymer insulation. Some emerging technologies are seeking an electric machine which would be able to operate in an ambient up to $500^{\circ} \mathrm{C}$, such as for more electric aircraft and downhole applications $[1,2]$.

Manuscript received on 20 June 2019, in final form 22 September 2019, accepted xx Month 20yy. Corresponding author: Y-X. Pang.
Modification of polymers with inorganic particles to form composites/nanocomposites has long been applied to enhance polymer properties, including thermal properties. Perspectives of polymer nanocomposites as dielectrics and electrical insulation was well reviewed by Tanaka $e t a l$ and the previous work reveals the nanocomposites may lead to improvements in electrical characteristics, resistance to high voltage environments and thermal endurance [3, 4]. The presence of a few percent nanoparticles in the nanocomposites significantly enhances resistance to partial discharge compared with the matrix polymers [5]. Morgan and Putthanarat reported thermal stability enhancement of a polyimide by incorporating fumed silica, alumina, carbon nanofibers and carbon nanotube or their combinations [6]. Wu et al modified a polyetherimide with aluminium nitride and achieved $49^{\circ} \mathrm{C}$ increase in glass transition temperature of the resultant composite containing $57.4 \mathrm{vol} \%$ aluminium nitride, along with about 8 fold increase in thermal conductivity [7]. Cao et al obtained $22^{\circ} \mathrm{C}$ higher decomposition temperature for a polyimide nanocomposite with reduced graphene oxide [8]. Thermal stability enhancement was also achieved for other polyimide matrix nanocomposites with layered silicate mineral particles such as montmorillonite, kaolinite and mica [911]. However, substantial enhancement of thermal decomposition 
temperature is not achievable through polymer-based composite/nanocomposite routes as the fundamental chemistry of organic polymer remains and dominates the materials properties.

For a long term application in an environment temperature above $300^{\circ} \mathrm{C}$, selection of inorganic insulation becomes inevitable. Some different technologies were employed to fabricate thin ceramic films over the years, among them sol-gel technology has been intensively exploited for its unique advantages of thin film forming capability and the versatile chemical compositions. For instance, sol-gel magnesia-zirconia high temperature insulation coatings were applied to insulate silver sheathed superconducting tapes and wires [12]; sol-gel aluminium oxide filled with alumina powders was used as thick film electrical insulation [13]; and sol-gel silica coatings was applied on anodised aluminium to fabricate ceramic insulated wires [14]. The drawback of ceramic insulation comes from the inherent brittleness of the materials which makes it difficult to meet the bending requirement for wire insulation.

Inorganic-organic nano-hybrids are a type of nanocomposite materials in which the inorganic and organic phases are mixed at molecular level and connected through covalent bonds. They are mostly derived from sol-gel chemistry using organofunctional metal alkoxides as precursors, usually organosilanes, rather than prepared from conventional blending processes [15, 16]. A variety of organic and inorganic components allows tailoring specific properties of the resultant nano-hybrids and more interestingly, synergetic effect is achievable due to the finer dispersion of the organic and inorganic phases [17]. We previously utilised siliconcontaining nano-hybrids with organic moiety of methyl as thermally stable coatings for fabrication of soft magnetic composites (SMC) and found that existence of the organic moiety imparts excellent compacting properties to SMC because of low surface energy of the nano-hybrid coating. The methyl group is removed during the annealing stage of compacted SMC, leaving a highly thermal stable silica insulating coating [18]. This work is to extend the concept for electrical wire insulation with high temperature capability. It is understood that good flexibility of the insulation of wires is essential at the stage of forming coils/windings, but less critical during the service stage of the electrical machine, though some flexibility is preferred for imparting good resistance to in service stresses. Where nano-hybrid composites are employed as wire insulation coatings, the organic moiety will provide interim mechanical flexibility to facilitate manufacturing processes such as winding, this organic component being later gradually removed in situ to produce an inorganic insulation coating on the wire surface that ensures ability to sustain high temperature, but with the composite structure still retaining limited but sufficient flexibility to withstand in service stresses such as from thermal cycling, vibration or electromagnetic forces. The sol-gel chemistry of the nano-hybrids allows both formation of silica through polycondenzation and the removal of the organic moiety. These processes gradually convert the ceramic/nano-hybrid composites into ceramic/ceramic (silica) composites in which the silica acts as a binder, contributing to the mechanical strength of resultant coatings. The nano scale distribution of the organic component used to provide initial mechanical flexibility for manufacturing, allows its removal without the formation of macroscopic defects, whilst the plate like composite structure imparts some degree of flexibility to the coating in its final form.

This work studies the molecular design of silicon-containing inorganic-organic nano-hybrids and their combination with particulate ceramics, as composite coating materials for electrical wire insulation.

\section{EXPERIMENTAL}

\subsection{MATERIALS}

Methyltrimethoxysilane (MTMS), phenyltriethoxysilane (PhTES), dimethyldiethoxysilane (DMDES), (3glycidyloxypropyl)trimethoxysilane (GPTMS), boric acid and phosphomolybdic acid (PMoA) were purchased from SigmaAldrich; 4-Hydroxy-4-methyl-2-pentanone (HMP), xylene, isopropanol, phosphoric acid and acetic acid from Fisher Scientific UK; vermiculite from Dupré Minerals Ltd UK; and copper and nickel-plated copper wires from vonRoll Isola Europe.

\subsection{PROCEDURE 2.2.1 Preparation of ceramic/nano-hybrid coating materials}

First, a nano-hybrid resin is synthesized using different organosilanes in a specified ratio. In a typical synthesis, charge MTMS 38.4g, GPTMS 3.5g, PhTES 0.7g and HMP 24g into a flask and stir the mixture vigorously; dissolve PMoA $0.6 \mathrm{~g}$ in deionized water $10.8 \mathrm{~g}$ and slowly drop the solution into the flask over about $1 / 2$ an hour. After addition, heat the reaction mixture to refluxing for 5 hours and then keep stirring overnight at room temperature to produce a viscous dark blue nano-hybrid resin solution. Other nano-hybrid resins with various compositions are synthesized in similar procedures.

In a parallel process, a vermiculite slurry is produced as follows: vermiculite $9.3 \mathrm{~g}$, mixed solvent $24 \mathrm{~g}$ (comprising HMP $40 \%$, xylene $30 \%$ and isopropanol $30 \%$ by volume) and acetic acid $0.05 \mathrm{~g}$ are charged into a porcelain jar with porcelain balls, ball-mill for 1 day.

The above synthesized nano-hybrid solution is then mixed with the vermiculite slurry ball milling for further 4 hours to ensure all ingredients are well dispersed, and thus produced a nanohybrid/ceramic coating material. Other composite coating formulations are prepared in the same way.

\subsubsection{Fabrication of coated wires}

The above-formulated coatings were applied on electrical wire through a so-called 'reel-to-reel' process, using a miniature wire coater made in our laboratory. First, the wire was dragged from the feed reel through a coating tank to dip-coat a thin layer of the coating material on its surface. Then the "wet" wire goes through a tunnel blowing $180^{\circ} \mathrm{C}$ hot air to dry out most of, the solvent and immediately goes into a furnace set at $200-360^{\circ} \mathrm{C}$ to cure the coating on the wire surface. Finally, collect the coated wire on the receiving reel.

The process repeats several times to build up desired insulation thickness. The processing temperature varies with coating material formulation. 


\subsection{CHARACTERIZATION AND MEASUREMENTS}

Particle size of ceramic powders was measured using AcoustoSizer II analyser, Colloidal Dynamics, USA, with water as the dispersing medium.

Thermal analyses were conducted using a Thermatrix STA-1500 TGA/DSC simultaneous thermal analyzer from room temperature to $900^{\circ} \mathrm{C}$ at the ramp $10^{\circ} \mathrm{C} / \mathrm{min}$ in static air or under argon flow of $30 \mathrm{~mL} / \mathrm{min}$.

The analysis of attenuated total reflectance Fourier transform infrared spectroscopy (ATR-FTIR) was conducted on a Thermo Nicolet 5700 FTIR spectrometer. All spectra were taken in wavenumber range between 400 and $4000 \mathrm{~cm}^{-1}$ at $4 \mathrm{~cm}^{-1}$ resolution, averaging over 32 scans.

Mechanical and dielectric measurements of insulated wires were tested according to the British Standard BS EN 60851.

\section{RESULTS AND DISCUSSION}

\subsection{PRELIMINARY EVALUATION OF SILICON- BASED NANO-HYBRIDS}

The overall objective of this study is to develop thin film coating materials for electrical wire insulation capable of withstanding temperature up to $500^{\circ} \mathrm{C}$, much beyond the temperatures conventional polymer enamels could withstand. Silicon-based nano-hybrid materials are chosen as the starting point considering that a variety of organosilanes are nowadays available at relatively low cost compared with other organic functional metal alkoxides and the nano-hybrid materials can be efficiently synthesized through simple sol-gel chemistry. A full spectrum of materials from hard ceramics to soft elastomers can be derived from organosilanes with the generic formula of $\mathrm{R}_{\mathrm{x}}-\mathrm{Si}\left(-\mathrm{OR}^{\prime}\right)_{4-\mathrm{x}}$ by defining $\mathrm{R}$ group and $\mathrm{x}$ value and/or combining different organosilanes with different $\mathrm{R}$ and $\mathrm{x}$, where $\mathrm{R}$ is a nonhydrolysable radical, OR' is hydrolysable alkoxy and $\mathrm{x}$ is an integer form $0-3$. The diagram below (Figure 1) briefly illustrates molecular structure and properties of sol-gel materials from silanes with different organic moieties. It is worth mention that of the $\mathrm{R}$ groups representing a variety of organic radicals, some are nonreactive, existing as organic inclusions in the resulting inorganic network, and others are reactive, forming organic polymer network coexisting with the inorganic network [16]. Obviously, incorporation of organic moiety introduces mechanical flexibility to the inorganic molecular networks, and at the same time reduces thermal stability of resulting nano-hybrid materials. However, these two conflicting parameters can be balanced at certain point to meet a specific application, e.g. electrical wire insulation with temperature endurance higher than polymer insulators could reach, whilst possesses better mechanical flexibility than inorganic insulators.

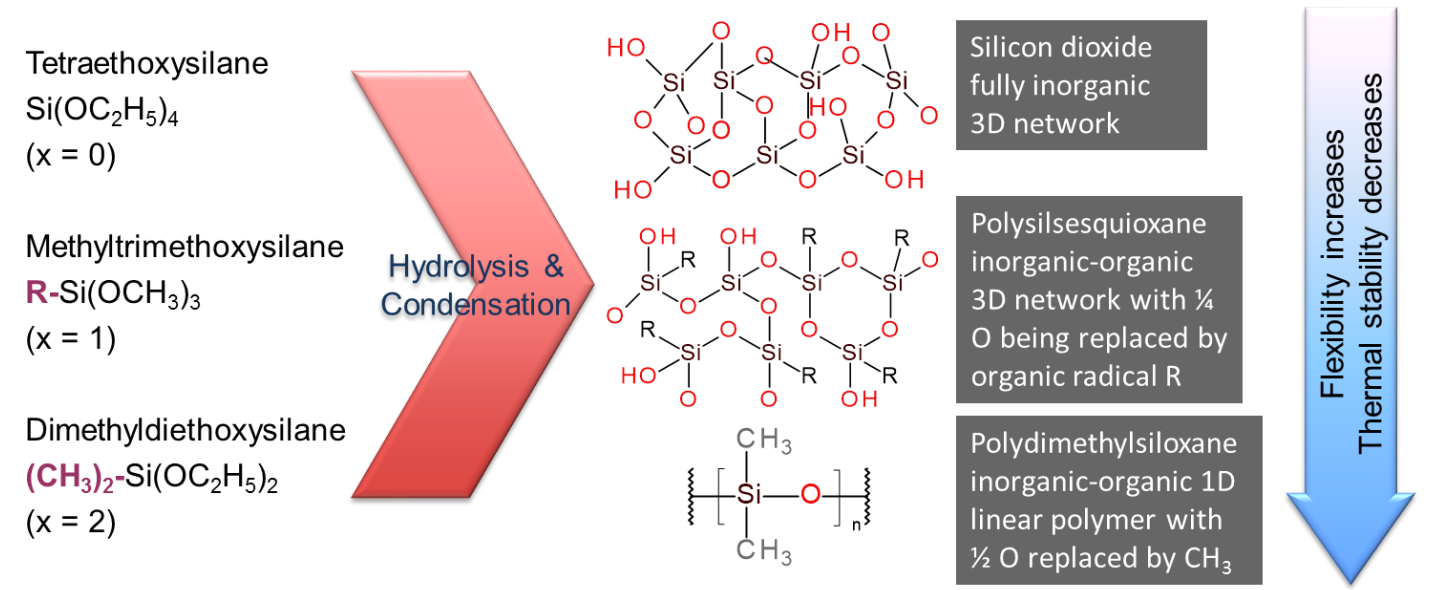

Figure 1. Illustration of versatile materials derivable from organosilanes $\mathrm{R}_{\mathrm{x}}-\mathrm{Si}(-\mathrm{OR})_{4-\mathrm{x}}$ with different $\mathrm{x}$ values $(0,1$ and 2$)$ through sol-gel processing.

Nano-hybrids of this study are designed from organosilanes with various $\mathrm{R}$ groups and $\mathrm{x}$ values and tailored for achieving optimal balance between thermal stability and mechanical flexibility. Nano-hybrids derived from MTMS through sol-gel processing are initially investigated as these were previously proved as thermally stable coatings [18, 19]. The methyl group attached to silicon through C-Si covalent bonding can withstand a temperature over $400^{\circ} \mathrm{C}$, as shown by the thermal analysis results in Figure 2 . The initial $2-3 \%$ weight loss below $200^{\circ} \mathrm{C}$ comes from drying out of moisture in the samples. The major weight loss when heated in oxidizing atmosphere (curve 1, black) begins just above $400^{\circ} \mathrm{C}$ and leads to an eventual weight loss of $10 \%$, close to the calculated weight loss of converting $\mathrm{CH}_{3} \mathrm{SiO}_{3 / 2}$ to $\mathrm{SiO}_{2}$ as expressed in the chemical oxidation Equation (1). Correspondingly, there is a large exothermic peak on the DSC curve, confirming the weight loss originates from thermally oxidative decomposition of methyl group in the nano-hybrid. Close inspection of the DSC data finds that the exothermic peak is unsymmetrical and the decomposing process lasts for nearly $200^{\circ} \mathrm{C}$ range. The sudden heat release at early stage with the decomposition onset temperature of $418^{\circ} \mathrm{C}$ results from burnout of surface methyl group, whilst the slower heat release at late stage arises from methyl groups embedded inside the inorganic silica network, which restricts penetration of oxygen. On the other hand, the material is stable up to $660^{\circ} \mathrm{C}$ when measured in protective atmosphere (plot 2, blue). The major weight loss is about $5 \%$, there is only a small hump on the corresponding DSC curve, reflecting about half of the decomposed products retained in the material, and the decomposing process is much less exothermic.

$$
2 \mathrm{CH}_{3} \mathrm{SiO}_{3 / 2}+4 \mathrm{O}_{2} \rightarrow 2 \mathrm{SiO}_{2}+2 \mathrm{CO}_{2}+3 \mathrm{H}_{2} \mathrm{O}
$$




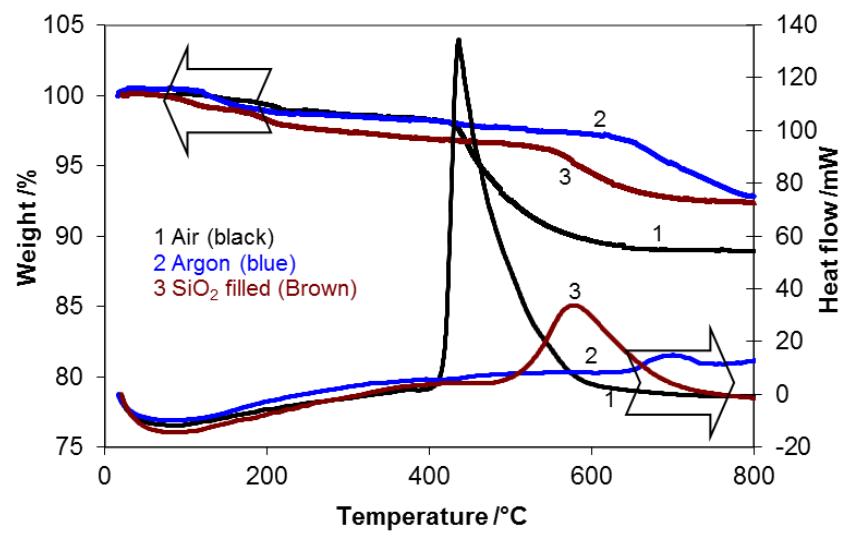

Figure 2. Thermal behavior of silicon-containing nano-hybrid synthesized from MTMS: 1 in air, 2 in argon and 3 filled with 50\% $\mathrm{SiO}_{2}$ powder, in air.

Figure 3 shows the ATR-FTIR spectra of nano-hybrid films after heat treatment at different temperatures. The absorption band at $1267 \mathrm{~cm}^{-1}$ attributes to the $\mathrm{C}-\mathrm{H}$ bond vibration in the $\mathrm{Si}$ $\mathrm{CH}_{3}$ structure remains unchanged up to $400^{\circ} \mathrm{C}$ and then the intensity goes down as increasing temperature of heat treatment [19]. The band position also moves slightly towards the high wavenumber side to $1272 \mathrm{~cm}^{-1}$ when heated at $500^{\circ} \mathrm{C}$ and above. Similar transform is observed for the absorption band at $758 \mathrm{~cm}^{-1}$, which assigns to the $\mathrm{Si}-\mathrm{O}$ and $\mathrm{Si}-\mathrm{CH}_{3}$ stretching, and nearly $10 \mathrm{~cm}^{-1}$ shift towards high wavenumber occurs from 450 and $500^{\circ} \mathrm{C}$, accompanied by the change in the peak intensity and sharpness. This type of band shifting has been reported by other researchers and was considered a reflection of the structural change resulting from the oxidative decomposition of organic group $[19,20]$. The relatively broad absorption band at $993 \mathrm{~cm}^{-1}$, which is also the contribution of $\mathrm{Si}-\mathrm{O}$ and $\mathrm{Si}-\mathrm{CH}_{3}$ stretching, remains intact up to $400^{\circ} \mathrm{C}$ and become sharp after heating at $450^{\circ} \mathrm{C}$ or higher. A shoulder at $1058 \mathrm{~cm}^{-1}$ develops at $500^{\circ} \mathrm{C}$ heating, indicating a structural change happens. Two other weak bands at 840 and $1103 \mathrm{~cm}^{-1}$ are retained at $450^{\circ} \mathrm{C}$ heating, but disappear at $500^{\circ} \mathrm{C}$ as the result of loss of methyl group. Similar changing trends are observed for the $\mathrm{C}-\mathrm{H}$ bond stretching at 2908 and $2967 \mathrm{~cm}^{-1}$ in high wavenumber range (spectra not shown here). In summary, the change of absorption bands characteristic of the organic moiety occur at heat treatment temperatures above $400^{\circ} \mathrm{C}$ and becomes significant between 450 to $500^{\circ} \mathrm{C}$.

This ATR-FTIR result is in good agreement with the thermal analysis, and both confirm the hybrid is thermally feasible for compounding insulators capable of withstanding up to $500^{\circ} \mathrm{C}$.

These silicon-containing nano-hybrids have excellent filmforming property and hence were initially evaluated as insulation coatings for electrical wires. Figure 4 depicts the coated copper wires with two nano-hybrids and both produce smooth, uniform and transparent coatings. However, their mechanical flexibility is significantly different. The nanohybrid synthesized from $100 \%$ MTMS cracks and partially spalls off the copper surface when bending on $2 \mathrm{~mm}$ diameter mandrel (Figure 4a), whilst the hybrid coating made from 80 mol\% MTMS and 20 mol\% DMDES remains intact under the same bending condition, showing corporation of more methyl groups makes the nano-hybrid more mechanically flexible.

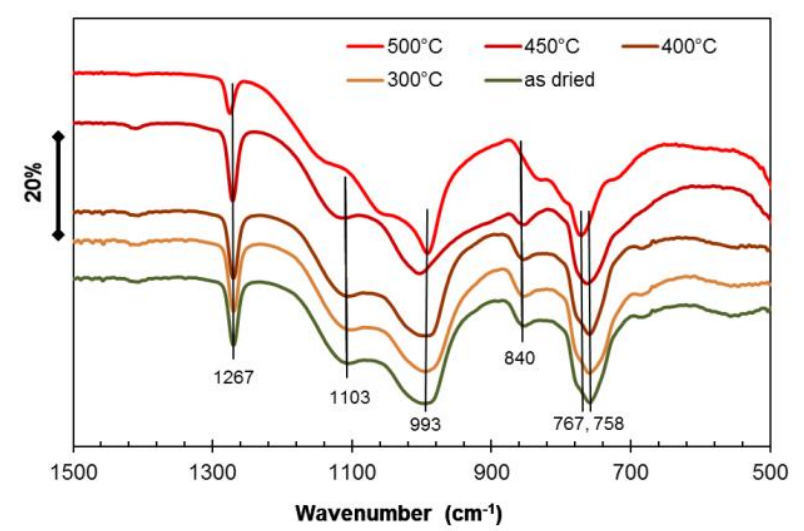

Figure 3. ATR-FTIR spectra of the hybrid from MTMS after heat treatment at various temperatures

Heat treatment of this nano-hybrid coated wire at different temperatures (Figures $4 \mathrm{c}-4 \mathrm{e}$ ) shows that the hybrid coating is stable up to $300^{\circ} \mathrm{C}$, but starts cracking at $350^{\circ} \mathrm{C}$ and more cracking develops after $400^{\circ} \mathrm{C}$ heating. Green spots are observed underneath the coating, indicating the oxidation of copper surface is occurring at higher temperatures. Cracks originate from significant volume shrinkage caused by the further condensation of silanol with the elimination of water this is the inherent drawback of sol-gel materials, suggesting the nano-hybrid alone cannot produce workable coatings for wire insulation.
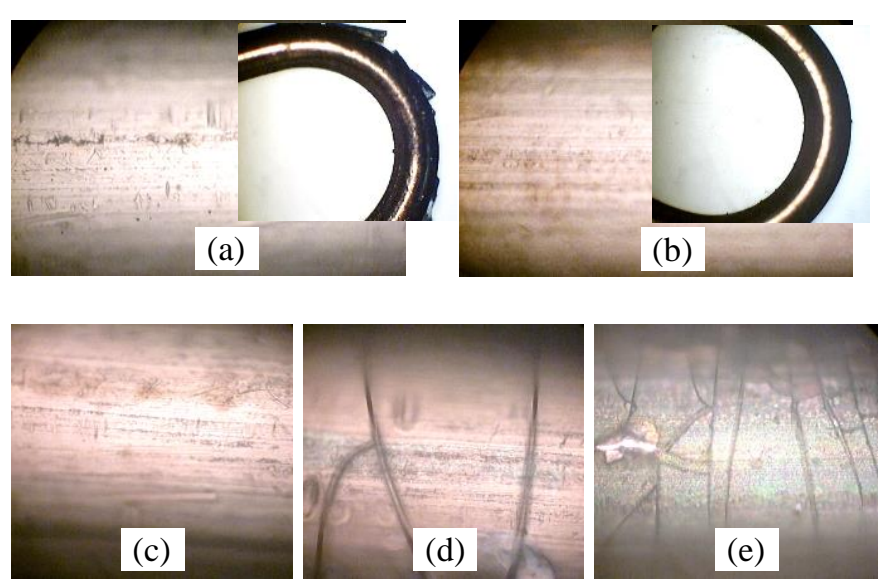

Figure 4. Optical micrographs of nano-hybrids coated $0.5 \mathrm{~mm}$ copper wires and their bending and thermal properties: (a) coating from 100\% MTMS; (b) coating from $80 \%$ MTMS and $20 \%$ DMDES, (c) heated at $300^{\circ} \mathrm{C}$, (d) $350^{\circ} \mathrm{C}$ and (e) $400^{\circ} \mathrm{C}$.

\subsection{PREPARATION OF COMPOSITE COATINGS}

\subsubsection{Design and synthesis of nano-hybrids}

The above preliminary investigation into silicon-based nanohybrids suggests they are feasible materials as thermally stable insulation for electrical wire. However, the results also reveal that these nano-hybrids on their own do not meet the requirements as high temperature insulation materials because coatings crack upon heating because of volume contraction. Incorporation of nonshrinking materials into the nano-hybrid will mitigate this problem and thus, composite coatings comprising the silicon-based nanohybrids and particulate ceramics are designed and studied in this 
work. In this case, nano-hybrids form the matrix phase and provide essential bonding to conductor wires and impart adequate mechanical properties required for coil / winding fabrication, whilst the particulate ceramics form the dispersed phase, which reduces the coating shrinkage during heat treatment, and at the same time, contribute extra dielectric strength to the composite coatings.

A number of nano-hybrids were thus designed using various organosilanes and systematically investigated with the aim to provide technological controls for making them optimal to the composite coatings. The finalized nano-hybrids were synthesized from MTMS in conjunction with some amounts of GPTMS and PhTES. Methyl is the smallest organic group and it may embed into inorganic network in the final nano-hybrid, so that it possesses better thermal stability compared with most other organic groups. Phenyl group has even higher temperature resistance because of the aromatic ring structure, so incorporation of this group is beneficial to thermal stability, but higher phenyl content leads to higher brittleness of the resultant nano-hybrids. The 3glycidyloxypropyl group can undergo polymerisation to form an epoxy polymer network, contributing to mechanical strength and flexibility of the resultant nano-hybrids. As mentioned previously, this epoxy polymer network is introduced as a sacrificial component, which offers adequate mechanical properties for coil winding or article making processes and then removed during later thermal ageing process. Figure 5 shows the removal of this epoxy polymer network and the formation of a ceramic-major composite coating with high temperature capability. For the as-made composite coating (green curves, containing the epoxy polymer), the gradual weight loss against temperature comes from the elimination of water formed during post polycondenzation of the nano-hybrid, whilst the sharp weight loss of circa $15 \%$ between $250^{\circ} \mathrm{C}$ and $400^{\circ} \mathrm{C}$ corresponds to burnout of epoxy polymer network (calculated value being $13 \%$ based on the 3glycidyloxypropyl content in the nano-hybrid). Correspondingly there is a distinct heat release peak on the DSC curve. For the $500^{\circ} \mathrm{C}$ heated sample, no stepped weight loss is observed on TGA curve and no heat transition peak shown on DSC curve because this portion of organic moiety has already been removed during $500^{\circ} \mathrm{C}$ heat treatment. The slight weight loss at lower temperature end $\left(<200^{\circ} \mathrm{C}\right)$ comes from the absorbed moisture.

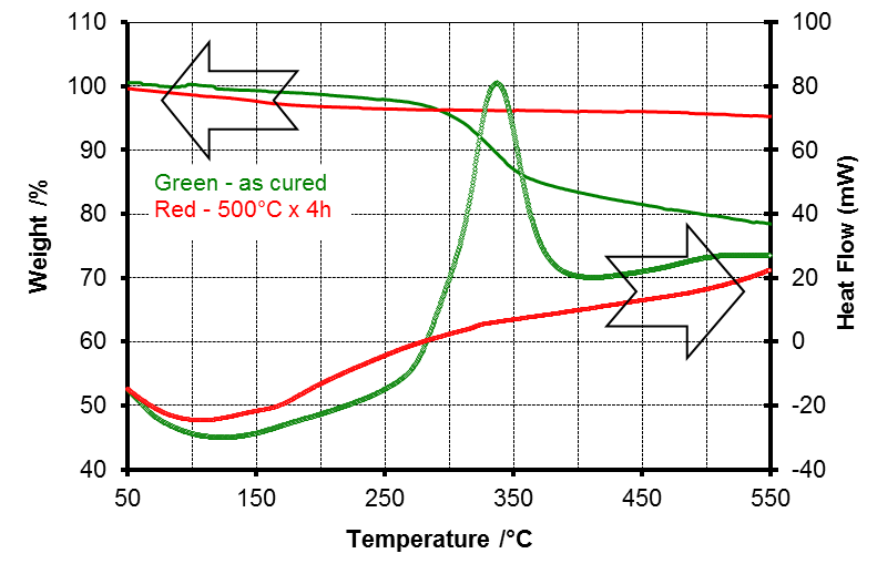

Figure 5. Thermal behavior of a composite coating prepared with a nanohybrid containing epoxy polymer of 3-glycidyloxypropyl.
Table 1. Optimal synthesis of nano-hybrids.

\begin{tabular}{|c|c|c|c|}
\hline $\begin{array}{l}\text { Organosilanes } \\
\text { (Mol. \%) }\end{array}$ & $\begin{array}{c}\mathrm{Si} / \text { Acid } \\
\text { (Molar ratio) }\end{array}$ & $\begin{array}{c}\mathrm{Si} / \mathrm{H}_{2} \mathrm{O} \\
\text { (Molar ratio) }\end{array}$ & $\begin{array}{l}\text { Organosilane / Solvent } \\
\text { Mixture (Mass ratio) }\end{array}$ \\
\hline MTMS 75-97 & PMoA 900 or & $1 / 1.6$ to & $2 / 1$ to $2 / 2$ \\
\hline $\begin{array}{l}\text { GPTMS } 3-25 \\
\text { PhTES } 0-5\end{array}$ & $\begin{array}{ll}\mathrm{H}_{3} \mathrm{PO}_{4} & 100 \text { or } \\
\mathrm{H}_{3} \mathrm{BO}_{3} & 33\end{array}$ & $1 / 2.4$ & $\begin{array}{l}\text { (HMP 40, Xylene } 30 \text { and } \\
\text { Isopropanol 30, vol. \%) }\end{array}$ \\
\hline
\end{tabular}

Apart from proper selection of organic moieties discussed above, there are some other parameters essentially important in order to produce the nano-hybrids with desirable properties. The extent of hydrolysis/condensation of organosilanes determines not only the molecular structure of nano-hybrids in the sol state, but also the property of final products and formation of gel [18]. For coating application of this study, proper hydrolysis/condensation extent leads to optimal properties of resultant nano-hybrids; higher or lower extent of hydrolysis resulting in mechanically brittle or weak products. The alkoxy-to-water ratio, catalysts and reaction conditions are all crucial factors influencing hydrolysis/condensation and are thus studied in this work. The main findings are summarized in Table 1.

Acid as the catalyst plays a very important role in sol-gel chemistry, from controlling hydrolysis and condensation of alkoxides to the resultant material properties. Phosphoric, phosphomolybdic and boric acids are compared in this study with their selection being on the basis that they are nonvolatile and may be converted into insulating oxides when heated to high temperature. They are all weak acids, among them boric acid is the weakest and phosphoric acid the strongest, which accounts for the different amount used in nano-hybrid syntheses. The nano-hybrids catalyzed by phosphoric acid and PMoA form uniform coatings on copper surface, whilst that catalyzed by boric acid produces a coating with some pores under the same condition. Bending test suggests the PMoA catalyzed nano-hybrid has the best mechanical flexibility among the three, whereas the boric acid catalyzed counterpart shows better cracking resistance after heat treatment at $450^{\circ} \mathrm{C}$. These results reflect the nano-hybrids are in different states of hydrolysis / condensation and probably have different molecular structure when using different acids as the catalyst.

Influence of organosilane-to-water molar ratios was tested within the range from $1: 1$ to $1: 3$ where water amount is not in stoichiometry but insufficiency. Experiments found that the ratio around 1:2 is optimal in regard to nano-hybrid properties and storage stability. Higher ratios, e.g. 1:1, cannot proceed to sufficient hydrolysis / condensation and lead to the nano-hybrid containing large amount of unreacted alkoxy groups, which are unable to form enough siloxane linkages during drying and curing, resulting in low molecular weight resins with poor mechanical strength. On the other hand, the nano-hybrids synthesised at high water content (1:3 ratio) are strong but brittle after curing because the alkoxy groups are supposed to be fully hydrolyzed and hence the nano-hybrids may proceed to form a dense inorganic network, resulting in a composite coating with poor mechanical flexibility. In addition, high water ratio tends to cause premature gelation of the sol, shortening coating shelf life. As a result, the ratio around $1: 2$ was found suitable for getting balanced properties of the nanohybrids. It is worthy to point out that the ratio may vary in relation to the organosilane composition. When more organosilanes bearing large $\mathrm{R}$ group are used, the water ratio is accordingly 
increased to compensate the reduction in reactivity caused by the steric effect of the large R groups [19].

Synthesis of nano-hybrids were carried out at very high organosilane concentration because week catalysts were employed. However, proper dilution with solvent is necessary for better control over the synthesis process, to prevent violent reaction which may lead to sudden gelation of the reaction mixture and to complete the synthesis in reasonable time scale. The concentration from 50 to $67 \mathrm{wt} \%$ was found suitable when the mixed solvent is used, which produce the optimal nano-hybrids under the operating conditions presented in Section 2.2.

\subsubsection{Selection of particulate ceramics}

Particulate ceramics constitute an equally important ingredient as the nano-hybrid in the composite coatings where they play dual functions - mitigating volume shrinkage and increasing thermal performance of the final composite coatings. Refractories like silica and alumina particles were firstly selected and found effective in reducing volume shrinkage and increasing thermal stability of the composite coating after heat treatment, as the example shown in Figure 2 that the silica/nano-hybrid composite demonstrated an enhanced thermal stability - the onset temperature of methyl group decomposition increased from $410^{\circ} \mathrm{C}$ to $505^{\circ} \mathrm{C}$ for the composite containing $50 \mathrm{wt} . \%$ silica. Stabilization of silicone resins by incorporating inorganic particles was reported in some other studies though the mechanism of thermal stability enhancement is to be clarified [19, 23]. However, the amount of ceramic phase is restricted because the composite coating becomes hard or less flexible with increasing ceramic particle loadings. To fully exploit benefits from ceramic component, layered silicate particles becomes the choice, because they are softer than silica or alumina. This type of materials comprises numerous tetrahedral and octahedral atomic sheets stacking together with an interlayer space, where the interlayer space can be empty, occupied by cations or even inserted with foreign molecules [24]. The expandable interlayer means the layers are movable relatively to one another, implying these plate particles are bendable in some way similar to a book, so that may lessen the hardening effect of inorganic phase on the mechanical flexibility of resultant composite coatings. In addition, enhancement in electrical insulation may be also envisaged because the ceramic platelets have high dielectric strength at the direction normal to the platelet plane and the overlapping packing of platelets in the composite coating structure minimises the possibility of developing conductive channels in the composite coating, in comparison with the irregularly shaped ceramic particles (Figure 6b). Mica, vermiculite and kaolin have been chosen as the ceramic phase to compound composite coatings with the nano-hybrids. All composite coatings from each of these three ceramic platelets produce uniform, crack-free insulations on conductor wires with excellent thermal stability and adequate mechanical flexibility. Among them, kaolin based composite coating has smoother surface finishing, whilst vermiculite based composite possesses the best mechanical bending performance, which probably comes from the lower Mohs' hardness of the material compared with the other two silicates Figure 6 shows some feature of vermiculite platelets studied in this work. Various size particles were tested and results show that this factor has marginal influence on the thermal and mechanical performance of the composite coating, rather the effect on coating finish if the particle is too big, such as the sample with median diameter of $5.3 \mu \mathrm{m}$ (blue plot in Figure 6a). The other three samples with smaller particle sizes produce similar surface smoothness as displayed by the micrographs of coated wires in Figure 7.
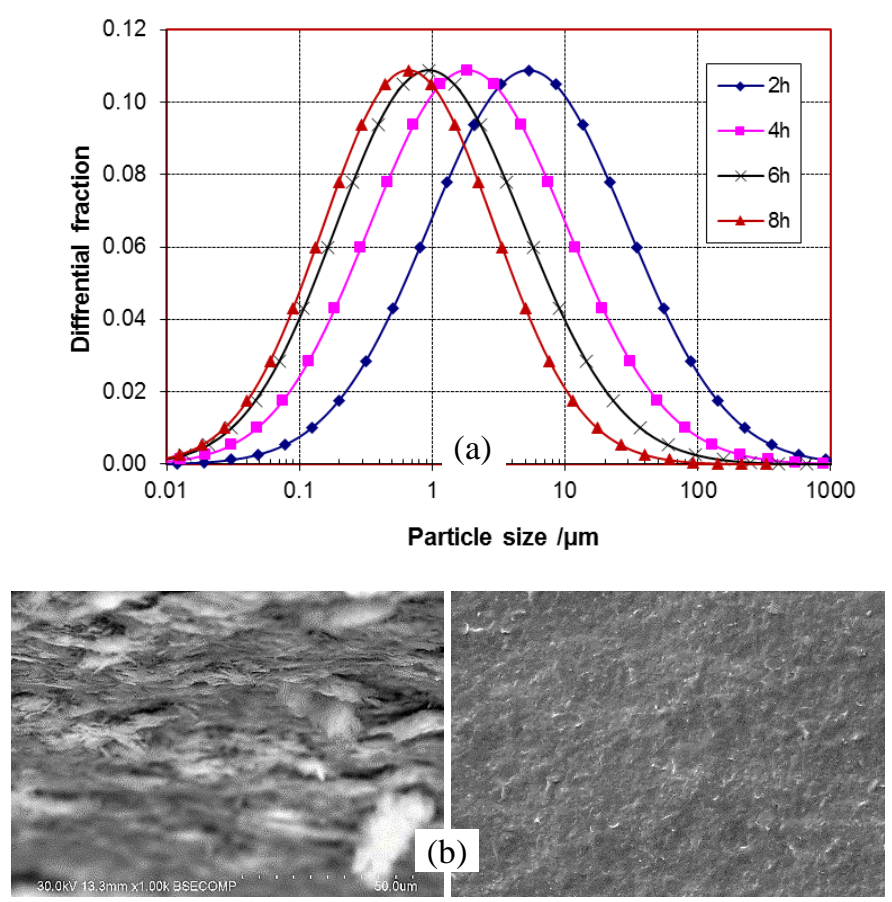

Figure 6. Characteristics of vermiculite plate particles for preparing composite coatings (a) particle size distribution, (b) packing of vermiculite layers (L: cross-section; R: top surface).

In preparation of the composite coatings, the nano-hybrids to ceramic platelet ratio is a crucial parameter and was studied in the range from 9:2 to 5:5 by mass. Higher ceramic phase is preferred in view of thermal performance and cost effectiveness. Experiments found that ceramic phase of $20 \mathrm{wt} \%$ is able to produce crack-free composite thin films up to $20 \mu \mathrm{m}$ thick, while greater than $50 \mathrm{wt} \%$ very much deteriorates the properties of the composite coatings, leading to reduced mechanical flexibility or large bending radius, reduced adhesion to conductor wire and less smooth surface finish. Platelet component amount in the range of $30-40 \mathrm{wt} \%$ is found optimal, resulting in smooth composite coatings with balanced dielectric, thermal and mechanical properties. Nano-hybrid composition and structure have certain influence on its capacity of incorporating ceramic platelets, those containing large organic moieties allow higher loading of platelet component, while sustaining mechanical performance of the composite coating.

\subsection{FABRICATION OF INSULATED WIRES}

The so-called reel-to-reel coating process was employed for applying composite coatings onto electrical conductor wires in an attempt to produce continuous insulated wires as well as to adapt the technique into commercial manufacture lines. We have built up a lab scale coater and systematically studied the effects of operating parameters on properties the coated wires in conjunction with the composite coating formulations. In general, results obtained suggest that the suitable processing conditions are: coating speed (wire travelling speed) $0.8-1.3 \mathrm{~m} / \mathrm{min}$, drying temperature $120-$ 
$200^{\circ} \mathrm{C}$ and curing temperature $200-360^{\circ} \mathrm{C}$. The relatively low coating speed comes from the short drying and curing paths of the coater. It was found important to match operating parameters with the viscosity of coating formulas. In summary, high viscosity formulas require low coating speed and drying temperature because the thick initial wet coating needs longer time to dry and the low temperature avoids forming pre-dried skin on wet coating surface. In addition, lower temperatures are preferred for nanohybrids containing larger $\mathrm{R}$ groups to prevent premature thermal oxidation.

Figure 7 illustrates a typical example of coated $1.2 \mathrm{~mm}$ diameter wire. The optical micrographs show that the coating on the wire has relatively smooth finish and moderate mechanical flexibility that allows the wire to be bent to a radius of $5 \mathrm{~mm}$ for this $40 \mu \mathrm{m}$ coating thickness (lower coating thickness allows smaller bending diameter and vice versa). The insulation remains almost intact without cracking development on the coiled and twisted wires after heating at $450^{\circ} \mathrm{C}$ for 10 hours as demonstrated in Figures $7 \mathrm{a}$ and $7 \mathrm{~b}$. The slight darkening of coating surface originates from the burnout of glycidyloxypropyl organic polymer from GPTMS according to its thermal property described in Figure 5. The composite coating survives after heat treatment at $500^{\circ} \mathrm{C}$, but starts cracking and spalling off from conductor wire when heating temperature rises to $550^{\circ} \mathrm{C}$ (Figure $7 \mathrm{~b}$ ).

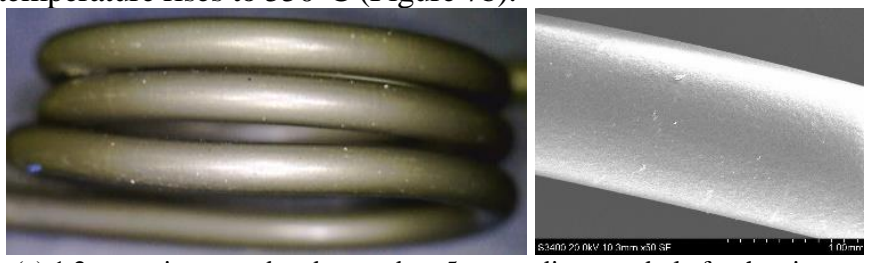

(a) $1.2 \mathrm{~mm}$ wire coated and wound on $5 \mathrm{~mm}$ radius mandrel after heating at $450^{\circ} \mathrm{C}$ for 10 hours (Left): Surface morphology of coated wire (right)

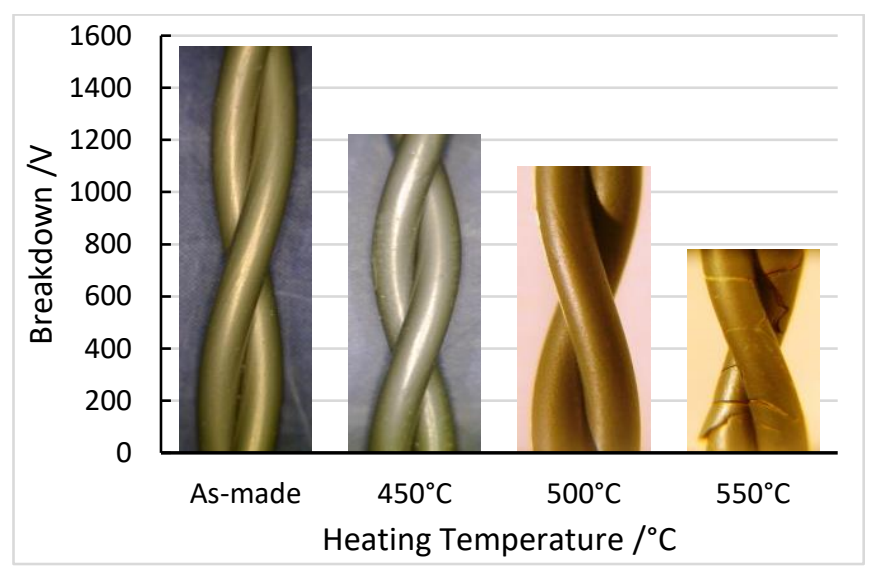

(b) Dielectric strength as a function of heating temperature

Figure 7. Mechanical flexibility, thermal stability and dielectric property of a typical composite coating insulated wire.

The breakdown voltage of the twisted pairs reduces after heat treatment due to the partial loss of organic moiety attached to the nano-hybrid of composite coating, as well as further polycondenzation of the nano-hybrids into silicon dioxide, both leading to reduced mass and volume of the insulation materials and thus the insulation thickness, with some corresponding but limited reduction in breakdown voltage. For this specific wire, the breakdown voltage retains at $1100 \mathrm{~V}$ after heating at $500^{\circ} \mathrm{C}$ for 4 hours, demonstrating the sample has excellent thermal stability and dielectric strength. However, the coating cracks and spalls after heating at $550^{\circ} \mathrm{C}$ due to the quick loss of the organic moieties.

\section{CONCLUSIONS}

This study successfully demonstrated the fabrication of electrically insulated wires, with thermal and dielectric properties comparable to ceramic insulated wires as well as initial moderate mechanical flexibility for coil winding, by mediating through composites comprising silicon-containing inorganic-organic nanohybrids and ceramic platelets.

This work systematically studied the composition and synthetic parameters of the silicon-containing nano-hybrids, the selection of ceramic platelets, the composite phase ratios, etc. and prepared composite coating formulas compatible to reel-to-reel coating process for producing insulated wires of continuous length. The coated electric wires are of balanced mechanical, thermal and dielectric properties. The interim mechanical flexibility imparted from the polymerized organic moieties of the nano-hybrids allow it to be processed similarly to polymer enamelled wire, whilst its subsequent sacrifice of the organic component leads to conversion of the nano-hybrid matrix into a ceramic/ceramic composite insulator bonded via a silica matrix ensuring ultrahigh temperature stability compared with polymer enamels. The silica network formed on in-situ heat treatment of the composite coated wire helps provide electrical integrity to the insulation and imparts mechanical integrity to the composite coating. Although the transition from organic bonded to silica matrix composite results in the loss of the full flexibility of the initial coated wire, the structure retains sufficient flexibility to withstand thermal cycling and operational mechanical stresses once fabricated, with this being a function of the plate like and relatively "soft" particulate silicate ceramic particles which form an integral element of the composite structure. The insulated wires have great potential to lift the temperature ratings of electrical machines and find applications in traditional sectors or emerging technological areas.

\section{ACKNOWLEDGMENT}

The authors gratefully appreciate the financial support of DTI Technology Programme with Project No. TP/2ET/6/I/10032, from the former Department of Trade and Industry, United Kingdom.

\section{REFERENCES}

[1] J. A. Rosero, J. A.Ortega, E. Aldabas L. Romeral, "Moving towards a more electric aircraft," IEEE A\&E Systems Magazine, vol.22, no.3, pp. 3-9, March 2007.

[2] J. Thompson, M. Rossing, "High-temperature downhole motor facilitates cleanout of obstructed thermal well, saving production downtime," SPE/ICOTA Coiled Tubing \& Well Intervention Conference and Exhibition, 2011.

[3] T. Tanaka, G. C. Montanari and R. Mülahulpt, "Polymer nanocomposites as dielectrics and electrical insulation - perspectives for processing technologies, material characterization and future applications," IEEE Trans. Dielectr. Electr. Insul., vol. 11, no. 5, pp. 763-784, Oct. 2004.

[4] T. Tanaka, "Dielectric nanocomposites with insulating properties," IEEE Trans. Dielectr. Electr. Insul., vol. 12, no. 5, pp. 914-928, Oct. 2005.

[5] X. Zhong, G. Wu, Y. Yang, X. Wu and Y. Lei, "Effects of nanoparticles on reducing partial discharge induced degradation of polyimide/Al2O3 
nanocomposites,” IEEE Trans. Dielectr. Electr. Insul., vol. 25, no. 2, pp. 594-602, Apr. 2018.

[6] A. B. Morgan and S. Putthanarat, "Use of inorganic materials to enhance thermal stability and flammability," Polymer Degradation and Stability, vol. 96, pp. 23-32, 2011.

[7] S-Y. Wu, Y-L. Huang, C-C. M. Ma, S-M. Yuen, C-C. Teng and S-Y. Yang, "Mechanical, thermal and electrical properties of aluminum nitride/polyetherimide composites," Composites: Part A, vol. 42, pp. 1573-1583, 2011.

[8] L. Cao, Q. Sun, H. Wang, X. Zhang and H. Shi, "Enhanced stress transfer and thermal properties of polyimide composites with covalent functionalized reduced graphene oxide," Composites: Part A, vol. 68, pp. 140-148, 2015.

[9] Z-M. Liang, J. Yin and H-J. Xu, "Polyimide/montmorillonite nanocomposites based on thermally stable, rigid-rod aromatic amine modifiers," Polymer, vol. 44, pp. 1391-1399, 2003.

[10] X. Qiu, H. Wang, C. Zhou, D. Li, Y. Liu and C. Yan, "Polyimide/kaolinite composite films: Synthesis and characterization of mechanical, thermal and waterproof properties, J. Taiwan Inst. Chem. Engineers, vol. 45, pp. 2021-2028, 2014.

[11] X. Cui, G. Zhu and W. Liu, "Synthesis, characterisation and enhanced properties of polyimide/mica nano-hybrid films," Plastics, Rubber and Composites, Macromolecular Engineering, vol. 46, pp. 35-41, 2017.

[12] E. Celik, I. H. Mutlu and Y. S. Hascicek, "Electrical properties of $\mathrm{MgO}-$ $\mathrm{ZrO} 2$ insulation coatings on $\mathrm{Ag}$ and $\mathrm{AgMg} / \mathrm{Bi}-2212$ tapes for magnet technology," Scripta Materialia, vol. 47, pp. 315-320, 2002

[13] T. Oldinga, M. Sayera and D. Barrow, "Ceramic sol-gel composite coatings for electrical insulation," Thin Solid Films, vol. 398-399, pp. 581-586, 2001.

[14] K. Sawnda, S. Inmwa and K. Yamada, "Insulated wire," US Patent $5,091,609,1992$.

[15] U. Schubert, N. Husing and A. Lorenz, "Nano-hybrid inorganic-organic materials by sol-gel processing of organofunctional metal alkoxides," Chem. Mater., vol. 7, pp. 2010-2027, 1995.

[16] K-H. Haas and H. Wolter, "Synthesis, properties and applications of inorganic-organic copolymers (ORMOCER $®$ s)," Current Opinion in Solid State and Materials Science, vol. 4, pp. 571-580, 1999.

[17] C. Sanchez, B. Julian, P. Belleville and M. Popall, "Applications of nano-hybrid organic-inorganic nanocomposites," J. Mater. Chem., vol. 15, pp. 3559-3592, 2005.

[18] Y. X. Pang, S. N. B. Hodgson, J. Koniarek, B. Weglinski, "The influence of the dielectric on the properties of dielectromagnetic soft magnetic composites. Investigations with silica and silica nano-hybrid sol-gel derived model dielectric," J. Mag. and Mag. Mater., vol. 310, pp 83-91, 2007.

[19] Z. Olejniczak, M. Leczka, K. Cholewa-kowalska, K. Wojtach, M. Rokita and W. Mozgawa, "29 Si MAS NMR and FTIR study of inorganicorganic hybrid gels," J. Molecular Structure, vol. 744-747, pp. 465-471, 2005.

[20] S. Nemeth and Y. C. Liu, "Mechanical properties of hybrid sol-gel derived films as a function of composition and thermal treatment," Thin Solid Films, vol. 517, pp. 4888, 2009.

[21] Y. R. Liu, Y. D. Huang and L. Liu, "Thermal stability of POSS/methylsilicone nanocomposites," Composites Science and Technology, vol. 67, pp. 2864-2876, 2007.

[22] D. A. Loy, B. M. Baugher, C. R. Baugher, D. A. Schneider and K. Rahhimian," Substituent effects on the sol-gel chemistry of organotrialkoxysilanes, Chemistry of Materials, vol. 12, pp. 3624-3632, 2000.

[23] W. H. Dickstein, R. L. Siemens and E. Hadziioannou, "Dynamic mechanical and thermogravimetric analyses of the effect of ferric oxide on the thermal oxidative degradation of silicon rubber," Therochim Acta, vol. 166, 137-145, 1990.

[24] M. F. Brigatti, D. Malferrari, A. Laurora and C. Elmi, "Structure and mineralogy of layer silicates: recent perspectives and new trends," EMU Notes in Mineralogy, vol. 11, Chapter 1, 1-71, 2011.

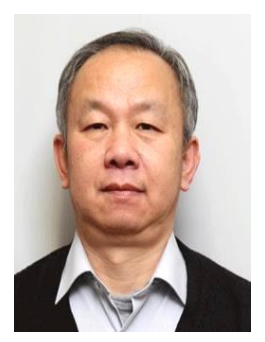

Y. X. Pang gained his $\mathrm{PhD}$ degree in polymer chemistry from Zhongshan University in 1988 . He is now a research senior lecturer in School of Science, Engineering and Design at Teesside University, UK. $\mathrm{He}$ is specialized in materials chemistry and has many years' research and development experience in advanced and functional materials through chemical, electrochemical and physical processing approaches. Current research interests include polymer and ceramic coatings with high temperature capability for electrical insulation and corrosion protection.

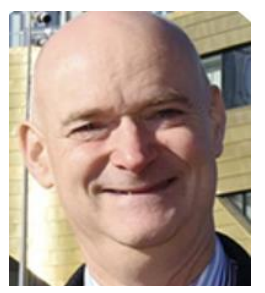

Simon N. B. Hodgson is Professor of Advanced Materials and Pro Vice-Chancellor for Research and Innovation at Teesside University. His specialist research field is in the area of inorganic and organicinorganic hybrid functional materials, coatings and nanocomposites by sol-gel, soft chemistry and related approaches together with their associated manufacturing processes. 